\title{
Endoscopic Transsphenoidal Resection of Craniopharyngioma
}

\author{
Kong Yew Liew ${ }^{1}$ Prepageran Narayanan ${ }^{2}$ Vicknes Waran ${ }^{3}$
}

\footnotetext{
1 Otorhinolaryngology Unit, Department of Surgery, Faculty of Medicine and Health Sciences, Universiti Putra Malaysia, Selangor, Malaysia

2 Department of Otorhinolaryngology, Faculty of Medicine, University of Malaya, Kuala Lumpur, Malaysia

${ }^{3}$ Neurosurgery Division, Faculty of Medicine, University of Malaya,

Kuala Lumpur, Malaysia
}

J Neurol Surg B 2018;79(suppl S2):S203-S204.

\begin{abstract}
Address for correspondence Vicknes Waran, MBBS, FRCS, Neurosurgery Division, Faculty of Medicine, University of Malaya, 50603 Kuala Lumpur, Malaysia (e-mail: cmvwaran@gmail.com).
\end{abstract}

\begin{abstract}
Keywords

- transsphenoidal

- craniopharyngioma

- intraoperative MRI

- third ventricle

- choroid plexus

Objectives To demonstrate, step-by-step, the technique and efficacy of endoscopic transsphenoidal approach in resection of a suprasellar craniopharyngioma.

Design The video shows a step-by-step approach to the resection, covering the exposure, access, resection, and confirmation of resection and reconstruction.

Setting The surgery was performed in the University of Malaya Medical Centre, a tertiary referral center in the capital of Malaysia.

Participants Surgery was performed jointly by Professor Prepageran from the department of otorhinolaryngology and Professor Vicknes Waran from the division of neurosurgery. Both surgeons are from the University of Malaya. Video compilation, editing, and voice narration was done by Dr. Kong Yew Liew.

Main Outcome Measures Completeness of resection and avoidance of intra- and postoperative complications.

Results Based on intraoperative views and MRI findings, the tumor was completely resected with the patient suffering only transient diabetes insipidus.

Conclusion Central suprasellar tumors can be removed completely via an endoscopic transsphenoidal approach with minimal morbidity to the patient.

The link to the video can be found at: https://youtu.be/ZNIHfk12cYg.
\end{abstract}

Conflict of Interest

None.

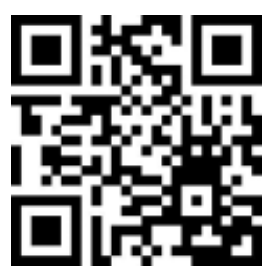

received

October 16, 2017

accepted

December 14, 2017

published online

January 16, 2018

www.thieme.com/skullbasevideos

www.thieme.com/jnlsbvideos

DOI https://doi.org/

10.1055/s-0037-1620243.

ISSN 2193-6331.
๑) 2018 Georg Thieme Verlag KG
Stuttgart · New York

License terms

(c) (1) $\ominus$ (\$) 


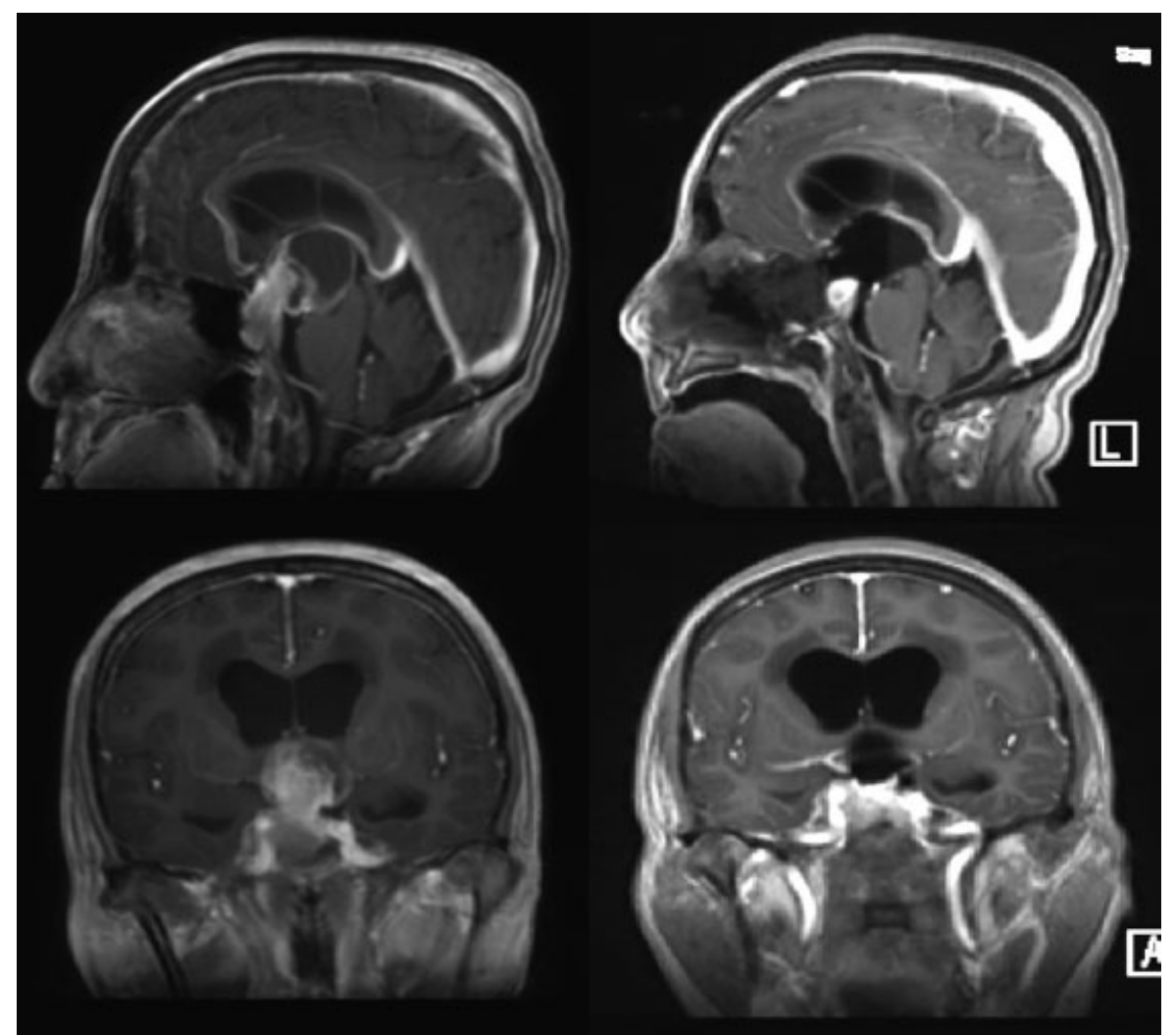

Fig. 1 Preoperative (left) and intraoperative (right) MRI images showing complete resection of the tumor. MRI, magnetic resonance imaging.

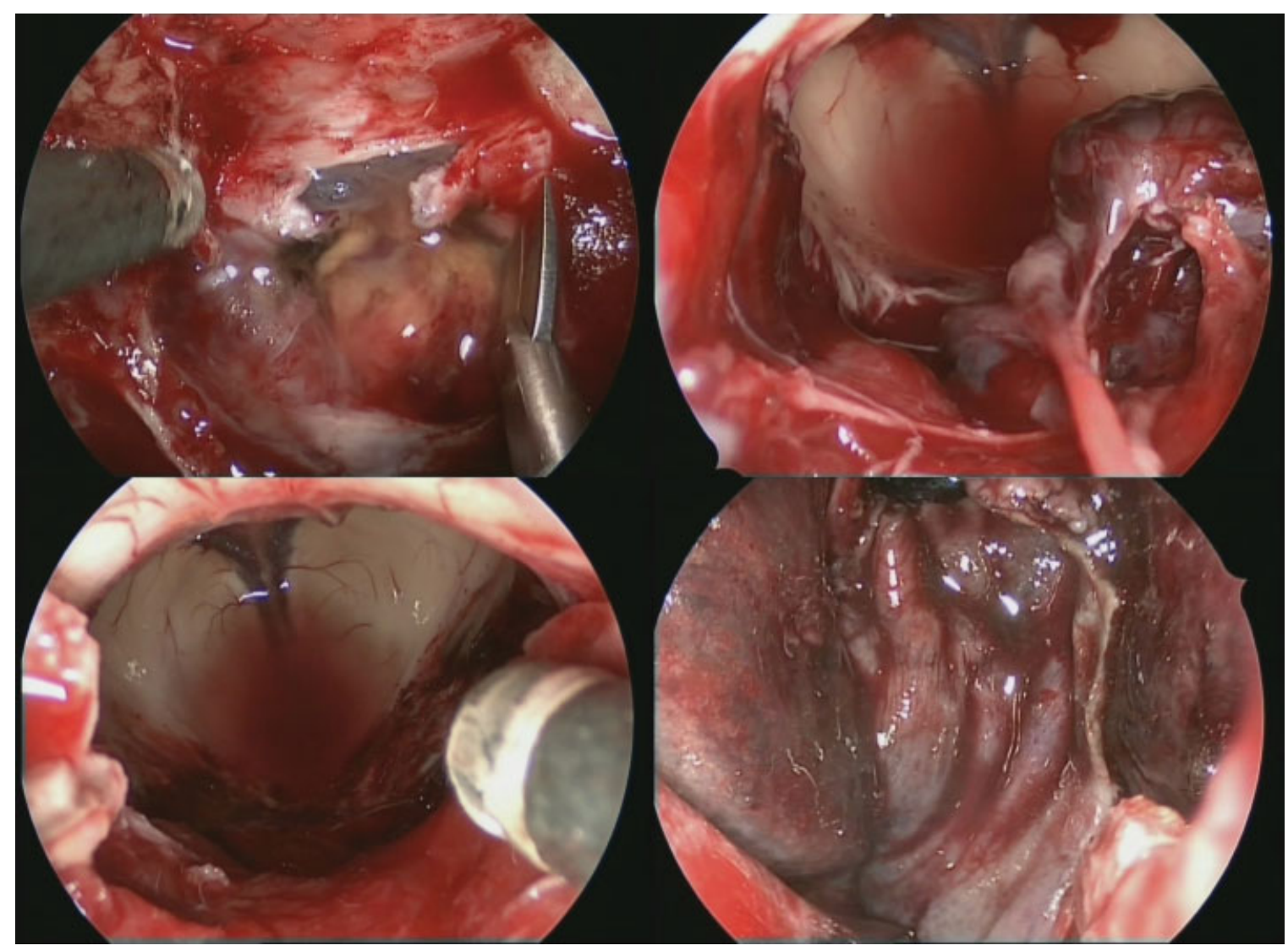

Fig. 2 Intraoperative views showing the step-by-step resection from the opening of the dura until the completed resection and reconstruction. 